\title{
Forced Expiratory Volume in 1 Second and Forced Vital Capacity in Bronchial Asthma Patients in Relation with Asthma Exercise
}

\author{
Atika Andianti, ${ }^{1}$ Vita Murniati Tarawan, ${ }^{2}$ Hendarsyah Suryadinata ${ }^{3}$ \\ ${ }^{1}$ Faculty of Medicine Universitas Padjadjaran, Indonesia, \\ ${ }^{2}$ Department of Biomedical Sciences Faculty of Medicine Universitas Padjadjaran, Indonesia, \\ ${ }^{3}$ Department of Internal Medicine Faculty of Medicine Universitas Padjadjaran/ \\ Dr. Hasan Sadikin General Hospital Bandung, Indonesia
}

\begin{abstract}
Background: Aerobic physical activity is one of the non-pharmacology management approaches of asthma. The Asthma Foundation of Indonesia (Yayasan Asma Indonesia, YAI) has designed an aerobic physical activity for people with asthma, known as Asthma Exercise. Asthma exercise is expected to increase the overall functional capacity of the lungs. One way to measure lung function is by measuring the score of forced expiratory volume in 1 second (FEV1) and forced vital capacity (FVC). The objective of the study was to explore the difference in FEV1 and FVC between bronchial asthma patients with and without asthma exercise.

Methods: This study involved asthma patients from the Bandung Asthma Association (Perhimpunan Asma Bandung, PAB) who did asthma exercise $(\mathrm{n}=28)$, and as control patients from the Pulmonology Clinic in Dr. Hasan Sadikin General Hospital were selected who did not do asthma exercise. The research data used were primary data from the spirogram examination. Asthma patients were selected based on inclusion and exclusion criteria. This research used unpaired numerical comparative analytical hypothetical tests with a cross-sectional design.

Results: The study showed the mean of FEV1 and FVC in the group with asthma exercise $1.6107 \pm 0.3780 \mathrm{~L}$ and $2.0396 \pm 0.3465 \mathrm{~L})$ was higher than the group without asthma exercise $(1.3750 \pm 0.4702 \mathrm{~L}$ and $1.7164 \pm 0.4632 \mathrm{~L})$. Statistical difference test using independent t-test indicated a score of $\mathrm{p}=0.044$ for FEV1 and $\mathrm{p}=0.005$ for FVC between the two groups.

Conclusions: There are significant differences in FEV1 and FVC between bronchial asthma patients with and without asthma exercise. Furthermore, asthma exercise is recommended for asthma patients to improve their lung function.
\end{abstract}

Keywords: Asthma exercise, FEV1, FVC

\section{Introduction}

Asthma is a heterogeneous disease characterized by chronic inflammation of the respiratory tract. The disease is characterized by a history of respiratory tract symptoms such as wheezing, shortness of breath, chest tightness, coughing, and various limitations of the airways during expiration that varies in time and intensity. ${ }^{1}$ These symptoms occur because of the inflammatory response in the respiratory tract obstructing the respiratory tract and causing bronchial hyperresponsiveness, which are the characteristics of functional abnormalities in patients with asthma. ${ }^{2}$ Asthma is a common respiratory disease, of which approximately $18 \%$ of the population with lung diseases accompanied by asthma. Asthma is estimated to cause an average of 250,000 deaths annually. ${ }^{3}$

Aerobic physical activity is one of the non-pharmacological treatments of asthma. ${ }^{1}$ It causes progressive desensitization to the feeling of breathlessness and greater control of asthma symptoms. ${ }^{4,5}$ Some studies showed that aerobic exercise causes an increase in Forced Expiratory Volume in 1 Second (FEV1) and Forced Vital Capacity (FVC) in patients with asthma. ${ }^{6}$

Aerobic physical activity designed specifically for people with asthma is called Asthma Exercise. Movements in asthma exercise area dapted to serve the capabilities and needs of the patient based on asthma severity. Previous

Correspondence: Atika Andianti, Faculty of Medicine, Universitas Padjadjaran, Jalan Raya Bandung Sumedang Km. 21 Jatinangor, Sumedang Indonesia, Email: atika0311@gmail.com 
research stated that there is an increase of lung function based on peak expiratory flow (PEF) measured by peak flow meter for about $11.9 \%$ in patients with asthma after doing asthma exercise for eight weeks in a row. ${ }^{7}$ Lung function can also be measured by FEV1 and FVC using spirometry examination. ${ }^{8}$ Aims of this study was to determine the differences in FEV1 and FVC values among bronchial asthma patients with and without asthma exercise.

\section{Methods}

This study used an unpaired comparative analytical method of two groups with a crosssectional approach. The sample size was based on the calculation of the minimum sample size by using the unpaired comparative analytic formula with significances of $\alpha=5 \%, \beta=90 \%$, $\mathrm{S}=0.3402$, and $\mathrm{X} 1-\mathrm{X} 2=0.3$, sample for each group which is 28.9 The population in this study was bronchial asthma patients divided into two groups: patients with asthma exercise and without asthma exercise.

The asthma exercise group consisted of bronchial asthma patients who were the members of the Bandung Asthma Association (Perhimpunan Asma Bandung, PAB). Inclusion criteria for the group with asthma exercise were the bronchial asthma patients in PAB who had performed asthma exercise for a minimum of eight weeks regularly. Patients with comorbid conditions, such as heart diseases, renal diseases, musculoskeletal diseases, and other lung diseases, pregnancy, and had performed any regular aerobic activity other than asthma exercise were excluded.

The control group consisted of bronchial asthma patients from the Pulmonology Clinic of Dr. Hasan Sadikin General Hospital. Inclusion criteria for the control group were the bronchial asthma patient in the Pulmonology Clinic of Dr. Hasan Sadikin General Hospital who had not performed asthma exercise. Patients with comorbid conditions, such as heart diseases, renal diseases, and other lung diseases, and who had performed any regular aerobic activity were excluded.

Data were obtained at Dr. Hasan Sadikin General Hospital from September until November 2015. Data on subjects' characteristics, history of the disease, history of asthma therapy, and control-based asthma classification were obtained from history taking. The height and weight of subjects were obtained from a physical examination.

Criteria for asthma classification was determined by asthma attack frequency in the past four weeks, which were daytime asthma symptoms more than twice per week, night waking due to asthma, need for a reliever for symptoms more than twice per week, and activity limitation due to asthma. Subjects were included in controlled asthma if subjects had none of these events, partially controlled asthma if subjects had 1-2 of these events,

Table 1 Characteristic of Bronchial Asthma Patients with or without Asthma Exercise

\begin{tabular}{|c|c|c|c|c|c|c|c|}
\hline \multirow{2}{*}{ Characteristics } & \multicolumn{3}{|c|}{ Asthma Exercise $(n=28)$} & \multicolumn{3}{|c|}{ Without Asthma Exercise(n=28) } & \multirow{2}{*}{ P-value } \\
\hline & $\mathbf{n}$ & Range & Mean \pm SD & $\mathbf{n}$ & Range & Mean \pm SD & \\
\hline Age (years) & & $32-72$ & $56.39 \pm 8.68$ & & $27-73$ & $49.03 \pm 11.16$ & 0.094 \\
\hline \multicolumn{8}{|l|}{ Sex } \\
\hline Male & 3 & & & 9 & & & \multirow[t]{2}{*}{0.001} \\
\hline Female & 25 & & & 19 & & & \\
\hline Weight (kg) & & $46-88$ & $62.17 \pm 9.84$ & & $40-136$ & $67.27 \pm 17.82$ & 0.080 \\
\hline Height $(\mathrm{cm})$ & & $141-170$ & $152.15 \pm 6.62$ & & $141.2-169$ & $154.3 \pm 6.79$ & 0.769 \\
\hline Body Mass Index $\left(\mathrm{kg} / \mathrm{m}^{2}\right)$ & & $19.56-33.9$ & $26.92 \pm 4.25$ & & $18.26-58.09$ & $28.34 \pm 7.73$ & 0.150 \\
\hline \multicolumn{8}{|l|}{ Asthma Classification } \\
\hline Controlled & 13 & & & 5 & & & \multirow{3}{*}{0.443} \\
\hline Partly Controlled & 11 & & & 14 & & & \\
\hline Uncontrolled & 4 & & & 9 & & & \\
\hline \multicolumn{8}{|l|}{ History of Asthma Therapy } \\
\hline Reliever & 11 & & & 14 & & & \multirow[t]{2}{*}{0.259} \\
\hline Controller & 17 & & & 14 & & & \\
\hline
\end{tabular}


Table 2 Data Distributions Normality Test

\begin{tabular}{|c|c|c|c|c|}
\hline & \multicolumn{4}{|c|}{ Group } \\
\hline & \multicolumn{2}{|c|}{ With Asthma Exercise $(\mathrm{n}=28)$} & \multicolumn{2}{|c|}{ Without Asthma Exercise $(n=28)$} \\
\hline & P-value & Data Distribution & P-value & Data Distribution \\
\hline FEV1* & 0.050 & Normal & 0.695 & Normal \\
\hline $\mathrm{FVC}^{* *}$ & 0.056 & Normal & 0.210 & Normal \\
\hline
\end{tabular}

Note: ${ }^{*} \mathrm{FEV} 1=$ forced expiratory volume in 1 Second, ${ }^{* *} \mathrm{FVC}=$ forced vital capacity

and uncontrolled asthma if subjects had 3-4 of these events. ${ }^{1}$

The FEV1 and FVC data were collected through spirometry measurements. It started by ensuring that all components of the spirometer were ready for use in the measurement. A mouthpiece was then inserted into the subjects' mouth. Subjects breathed normally three times. Subjects then subsequently performed maximal inspiration and maximal expiration as perfect as possible and as soon as possible from the mouth to the mouthpiece in an upright body position. The start button was then pressed at the same time as the subjects began to perform expiration. Measurement results of FEV1and FVC could be seen on the spirometer screen, showing a curve of the relationship between time (second) and lung volume change (liter), and on the print out of spirogram.

Data were analyzed with the homogeneity test of the subjects by using Levene's Test for Equality of Variace $(p \geq 0.05)$. Homogeneity of the subjects was based on age, sex, weight, height, body mass index, control-based asthma classification, and history of asthma therapy. The normality of data distribution was tested by using Shapiro-Whilk ( $>0.05)$ because the sample size was less than 50 per group. Independent $t$-test would be used if data were normally distributed, otherwise the MannWhitney test would be used. Statistical analysis is considered significant with a value of $p<0.05$. The data were processed and analyzed using Microsoft Excel 2007 and Version 15.0 of Statistical Passage for Social Sciences (SPSS). Data were displayed in tabular forms.

This study was conducted after obtaining approval from the Health Research Ethicsl Committee of Dr. Hasan Sadikin General Hospital with a number of LB.04.P1/A05/ EC/268/VII/2015. Examination of the subjects performed after the subjects were given explanations about the research procedures and had signed informed consent forms voluntarily. The subjects had the freedom to withdraw from participation in the research with no further consequences. Confidentiality was maintained during the research project.

\section{Results}

Homogeneity of the subjects was tested by using Levene's Test for Equality of Variance. Table 1 showed the general characteristics of the subjects; age, weight, height, body mass index, asthma classification, and medical history resulted in $p \geq 0.05$, indicating these characteristics were homogenous. The characteristics of the subjects in sex resulted in $\mathrm{p}<0.05$, indicating these characteristics were non-homogenous.

Saphiro Wilk test was performed to analyze whether the FEV1 and FVC data were distributed normally. Table 2 showed the value of $p \geq 0.05$, indicating the data were normally distributed.

Hypothesis testing for differences in FEV1 and FVC between the two groups conducted with an independent t-test. Table 3 showed the results of hypothesis testing showed the value of $\mathrm{p}<0.05$ for both FEV1 and FVC, indicating there were significant differences in FEV1 and FVC between bronchial asthma patients with and without asthma exercise.

\section{Discussion}

Characteristics of the subjects based on the results of Levene's Test for Equality of Variance showed homogeneous characteristics based on age, weight, height, body mass index, asthma classification, and history of asthma treatment for $\mathrm{p} \geq 0.05$, while characteristics based on sex were non-homogenous because the $p$-value was $<0.05$. The FEV1 and FVC values tend to increase with age until 20 years old in females and 25 years old in males, then gradually decreased in general. The greater decline in FEV1 than FVC causes the age-related fall in FEV1/FVC in adults. ${ }^{10}$ The trend of asthma was reversed after adolescent which higher in females than males. The airway caliber and lung function of male adults are greater than 
Table 3 FEV1 and FVC between Bronchial Asthma Patients with or without Asthma Exercise

\begin{tabular}{|c|c|c|c|}
\hline & \multicolumn{3}{|c|}{ FEV1* } \\
\hline & With Asthma Exercise $(n=28)$ & Witho & hma Exercise $(n=28)$ \\
\hline \multicolumn{4}{|l|}{ FEV } \\
\hline Mean (L) & 1.6107 & & 1.3750 \\
\hline Standard Deviation & 0.3780 & & 0.4702 \\
\hline P-value & \multicolumn{3}{|c|}{0.044} \\
\hline Mean Difference & \multicolumn{3}{|c|}{0.2357} \\
\hline 95\% Confidence Interval & \multicolumn{3}{|c|}{$0.0071-0.4643$} \\
\hline \multicolumn{4}{|l|}{ FVC } \\
\hline Mean (L) & 2.0396 & & 1.7164 \\
\hline Standard Deviation & 0.3465 & & 0.4632 \\
\hline P-value & \multicolumn{3}{|c|}{0.005} \\
\hline Mean Difference & \multicolumn{3}{|c|}{0.3232} \\
\hline 95\% Confidence Interval & \multicolumn{3}{|c|}{$0.1040-0.5424$} \\
\hline
\end{tabular}

Note: *FEV1= Forced Expiratory Volume in 1 Second, ${ }^{* *}$ FVC= Forced Vital Capacity

female adults. The smaller airway caliber in females causes increases in airway resistance and $\mathrm{CO}^{2}$ retention in blood. In general, female sex hormones aggravate asthma and other allergic diseases, whereas male sex hormones suppress such diseases. Females also seem to be born with $\mathrm{Th}^{2}$ bias, which is important in asthma pathophysiology. Female sexhormones, such as progesterone and estrogen increase the secretions of interleukin- 4 and total IgE levels. Stress and concern about eating habits that cause obesity to develop more frequently in females. The relation between obesity and asthma is explained by several mechanisms, which are mechanical factors such as lower lung volume and compliance and smaller diameter of the peripheral airways; systemic inflammation caused by fat-cell-secreting adipokines including IL-6, tumor necrosis factor (TNF)- $\alpha$ and eotaxin; a decrease in adiponectin, an obesity hormone with an anti-inflammatory effect; and an increase of oxidative stress. ${ }^{11}$

Data distributions based on the results of Saphiro Whilk test showed the FEV1 and FVC data were distributed normally because the $p$-value was $\geq 0.05$. An independent t-test was used for hypothesis testing because the data were normally distributed. Results from the independent t-test showed there were differences in FEV1 and FVC values between bronchial asthma patients with and without asthma exercise. These can be seen from the mean difference of $0.2357 \mathrm{~L}$ for FEV1 and
$0.3232 \mathrm{~L}$ for FVC between the two groups. The differences in FEV1 and FVC between the two groups in this study were statistically significant $(\mathrm{p}<0.05)$. These results are supported by several previous studies. A study conducted by Farid R et al. ${ }^{6}$ in Iran aimed to see the results of aerobic activity intervention on the subjects with asthma and it showed that the intervention impact changes in FEV1 and FVC between the exercise and control groups were statistically significant $(\mathrm{p}<0.05)$. Another study conducted by Sahat CS et al. ${ }^{7}$ in West Java by giving asthma exercise intervention for subjects with asthma showed that there were significant differences with $p<0.05$ in both FEV1 and FVC between the exercise and control groups.

Vital lung capacity is affected by the habit of doing physical activity or aerobic exercise. The volume and pattern of respiratory ventilation are regulated by the respiratory center in the brain stem by sending nerve impulses through the intercostal muscles and the diaphragm. The respiratory center in the brain stem is stimulated by the proprioceptive receptors in moving muscles, tendons, and joints when a person performing the aerobic activity. Stimulation of the respiratory center by aerobic activity will increase the rate and depth of breathing to improve the FVC, oxygen consumption, and the rate of diffusion of oxygen. $^{8}$

Aerobic activity, or in this study is in the form of asthma exercise, affects lung function 
by increasing blood flows through the lungs including respiratory muscles so that the volume of oxygen that diffuses into the pulmonary capillaries is larger or maximum and oxygen consumption in the blood is increased. ${ }^{9,12}$ Blood flows carry oxygen and nutrients such as calcium and potassium to the respiratory muscles. Calcium ions in the muscles are increased due to an increase in calcium ions released by the sarcoplasmic reticulum. Calcium ions serve to a muscle action potential and increase the work of respiratory muscles so that muscles mass can be maintained, furthermore improve the strength of the respiratory muscles resulting in improvement of pulmonary ventilation, lung compliance, and reduction of the amount of air trapped in the lungs and respiratory tract resistance. ${ }^{7,8}$ Also people with asthma will be forced to perform a deep inspiration that fills the entire airway with air after the completion of asthma exercise. ${ }^{8}$ This results in sufficient inspiratory pressure for maximum ventilation so the air movement is better even though the amount of breathing is less. ${ }^{12}$

Increased lung volume after a maximum inspiration will increase the amount of air that can be forcibly expelled in the first second after a maximal inspiration so that the FEV1value increases. ${ }^{3}$ Research by Handayani et al. ${ }^{13}$ showed that asthma exercise can cause an increase of cortisol secretion by the adrenal cortex, resulting in an increased response of beta-adrenergic receptors on smooth muscles of the respiratory tract, furthermore reducing hyperresponsiveness of respiratory tract due to decreased amount of circulating eosinophils and also inhibiting the production of cytokines in the respiratory tract. Previous studies in animal models of asthma stated that aerobic exercise causes a decrease of eosinophils and airway inflammation and remodeling. This happens due to decreased expression of $\mathrm{Th}^{2}$ cytokines (IL-4, IL-5, and IL-13) and NF-JB and increased expression of anti-inflammation cytokines, which are IL-10 and IL-1ra. ${ }^{14,15}$ Reduced airway inflammation and remodeling cause the expansion of the respiratory tract to increase, there by improving the score of FEV1. ${ }^{13}$

Improved lung function by asthma exercise influences a decrease in asthma symptoms and an increase in the ability of asthmatics to undertake daily physical activity. ${ }^{16}$ Increased capacity of oxygen uptake while breathing causes desensitization to breathlessness which increases the threshold when the asthma symptom is felt. ${ }^{17}$ Asthma exercise can improve residual airflow and decrease breathing ventilation, these are accompanied by the strengthening of the expansion of the bronchus so that the air will be in the lung at longer intervals in between breaths during exercise. ${ }^{6,14}$ This results in more powerful and effective inspiration and expirationin patients with asthma. Furthermore, tolerance to physical activity will also be increased from time to time. ${ }^{17}$

Significant differences in FEV1 and FVC between bronchial asthma patients with and without asthma exercise were marked in the subjects in the asthma exercise group, who had performed a regular exercise for eight weeks period. Long-term exercises cause the change of plasticity of airway smooth muscle cytoskeleton or the interaction of myosin and actin, furthermore enable the smooth muscle fibers to become more resistant to spasmogens. Habitual exercises cause the reorganization of the contractile apparatus of the airway smooth muscle which enables the smooth muscle fibers to adapt to changes in cell shape. A previous study of the animal models showed that habitual exercise increases the thickness of epithelial cells and the number of proliferating bronchiolar epithelial cells. ${ }^{18}$ The long term aerobic training also leads to increased capillarization of the muscle; therefore, the more oxygen-rich blood supply can be delivered to the working muscles. The result of this research is also consistent with a study conducted by Farid R et al. ${ }^{6}$ stated there are improvements of FEV1 and FVC after the research subjects undertook two monthsprogrammed aerobic activities regularly. Sahat et al. ${ }^{7}$ also conducted a similar study providing asthma exercise intervention for 8 weeks and showed significant differences in FEV1 and FVC between the intervention and control groups.

The limitation of the study is that this study was carried out at one time and in two different population groups that may affect the homogeneity of the characteristics of the subject. Recall bias may occur when patients filled out the datasheet associated with asthma manifestations to determine controlbased asthma classification of the patients. The future longitudinal study is needed to determine the effect of asthma exercise on lung function measured by FEV1 and FVC.

As a conclusion, there are significant differences in lung function between bronchial asthma patients with and without asthma exercise. Therefore, health service should not only focus on providing interventions for 
asthma patients pharmacologically but also non-pharmacologically, including exercise regularly. It is suggested that PAB follows up the member's regularity to asthma exercise every week is recommended to improve lung function in an asthma patients.

\section{References}

1. Global Initiative for Asthma. GINA reports 2015, Global Strategy For Asthma Management and Prevention. Fontana USA: Global Initiative for Asthma; 2015.

2. Global Initiative for Asthma. GINA reports 2012, Global Strategy For Asthma Management and Prevention. Fontana USA: Global Initiative for Asthma; 2012.

3. Nikmah SN, Purba A, Defi IR. Efektivitas latihan Incentive Spirometry dengan latihan pernapasan diafragma terhadap fungsi paru, kapasitas fungsional, dan kualitas hidup penderita asma bronkial alergi. MKB. 2014;46(1):39-47.

4. McArdle WD, Katch FI, Katch VL. Exercise physiology: nutrition, energy, and human performance. $7^{\text {th }}$ ed. Philadelphia: Lippincott Williams \& Wilkins; 2010.

5. Dogra S, Kuk J, Baker J, Jamnik V. Exercise is associated with improved asthma control in adults. Eur Respir J. 2011;37(2):318-23.

6. Farid R, Azad FJ, Atri AE, Rahimi MB, Khaledan A, Talaei-Khoei M, et al. Effect of aerobic exercise training on pulmonary function and tolerance of activity in asthmatic patients. Iran J Allergy Asthma Immunol. 2005;4(3):133-8.

7. Sahat CS, Irawaty D, Hastono SP. Peningkatan kekuatan otot pernapasan dan fungsi paru melalui senam asma pada pasien asma. JKI. 2011;14(2):101-6.

8. Fatima SS, Rehman R, Saifullah, Khan Y. Physical activity and its effect on forced expiratory volume. J Pak Med Assoc. 2013; 63(3):310-2.

9. Hutapea MD, Angliadi A. Perbandingan FEV1 (Forced Expiratory Volume In One
Second) pada mahasiswa yang aktif dan tidak aktif berolahraga. Jurnal eclinic. 2013;1(1).

10. Sharma G, Goodwin J. Effect of aging on respiratory system physiology and immunology. Clin Interv Aging. 2006;1(3): 253-60.

11. Choi IS. Gender-specific asthma treatment. Allergy Asthma Immunol Res. 2011;3(2): 74-80.

12. Raton R, Polii R, Marunduh SR. Pengaruh latihan aerobik terhadap forced expiratory volume in one second (FEV1) pada mahasiswa pria dengan kelebihan berat badan (Overweight). Jurnal e-Biomedik. 2013;1(2):884-9.

13. Handayani RN, Agustiningsih D, Djunaedi A. Effect of swimming and asthmatic exercise on forced expiratory volume in 1 second (FEV1) and levels of cortisol hormone in asthmatic patients. J Med Sci. 2012;44(1):78-83.

14. Mendes FA, Almeida FM, Cukier A, Stelmach R, Jacob-Filho W, Martins MA, et al. Effects of aerobic training on airway inflammation in asthmatic patients. Med Sci Sports Exerc. 2011;43(2):197-203.

15. Vieira RP, Claudino RC, Duarte AC, Santos $\hat{A} B$, Perini A, Faria Neto HC, et al. Aerobic exercise decreases chronic allergic lung inflammation and airway remodeling in mice. Am J Respir Crit Care Med. 2007; 176(9):871-7.

16. Turner S, Eastwood P, Cook A, Jenkins S. Improvements in symptoms and quality of life following exercise training in older adults with moderate/severe persistent asthma. Respiration. 2011;81(4):302-10.

17. Heikkinen SA, Quansah R, Jaakkola JJ, Jaakkola MS. Effects of regular exercise on adult asthma. Eur J Epidemiol. 2012; 27(6):397-407.

18. Scichilone N, Morici G, Zangla D. Effects of exercise training on airway responsiveness and airway cells in healthy subjects. J Appl Physiol (1985). 2010;109(2):288-94. 